\title{
AVANCES EN LA CONSTRUCCIÓN DEL DERECHO ECLESIÁSTICO COMO DISCIPLINA JURÍDICA EN PERÚ
}

\author{
PROGRESS TO IMPROVE THE CIVIL ECCLESIASTICAL LAW AS \\ ACADEMIC DISCIPLINE IN PERU
}

\section{SusAna Mosquera}

\begin{abstract}
RESUMEN: Este ensayo tiene como objetivo presentar los avances que la disciplina académica del derecho eclesiástico ha tenido en el ordenamiento jurídico peruano desde la aprobación de la Ley de libertad religiosa. La jurisprudencia reciente emanada del Tribunal Constitucional y la necesidad de atender a cuestiones jurídicas que derivan de la composición ideológicamente plural de la sociedad peruana, hacen visible la importancia que tiene construir con criterios académicos las bases del modelo peruano de relaciones Iglesia Estado. Pues como rama jurídica, el derecho eclesiástico tiene una gran proyección de futuro para la solución de conflictos que derivan de la convivencia multicultural.
\end{abstract}

Palabras clave: Libertad religiosa, pluralismo ideológico, derecho eclesiástico, relaciones Iglesia-Estado.

ABSTRACT: This paper has the purpose to present how the civil ecclesiastical law have progressed as academic discipline in Peru after the enactment of the Law of Freedom of Religion. Peruvian Constitutional Court recent sentences and the requirement to attend the legal consequences of having an ideologically multicultural society have pointed out how important is to correctly describe the Peruvian Church and State relationship model. Civil Ecclesiastical Law proved to be really useful to solve current conflicts in multicultural societies.

Key words: Religious freedom, ideological pluralism, civil ecclesiastical law, Church and State relationship.

\section{UNA MUY BREVE APROXIMACIÓN ACADÉMICA AL CONCEPTO DE DERECHO ECLESIÁSTICO DEL ESTADO}

La denominación de la disciplina académica "derecho eclesiástico" en los planes de estudio de la universidad española fue una herencia directa de la tradición académica italiana; siendo este doble legado, italo-español, el que se recibe en la América de influencia hispana a la hora de nombrar esa normativa civil sobre cuestiones religiosas ${ }^{1}$. La Universidad de Piura es uno de los pocos centros universitarios de América Latina que tienen en su plan de estudios de derecho un curso obligatorio dedicado al estudio del derecho eclesiástico ${ }^{2}$. $\mathrm{Y}$ aunque durante un tiempo se impartió, un contenido más afín al derecho canónico, lo

\footnotetext{
1 Sobre la denominación de esta disciplina puede verse, GonZÁlEz (1997), pp. 55 y ss.

2 Mención especial hay que hacer al caso chileno donde el trabajo de destacados profesores ha logrado posicionar los temas propios del derecho eclesiástico en el debate académico de primer nivel. Véase las obras, Salinas (2004); Pacheco (2004), así como los trabajos de Ana María Celis, Jorge del Picó, Carmen Domínguez, Jorge Precht o María Elena Pimstein entre otros.
} 
cierto es que desde la aprobación de la Ley 29.635 de libertad religiosa, el objeto de estudio de la asignatura está centrado en la aplicación de los principios que vertebran el modelo peruano de relaciones entre el poder político y religioso, el desarrollo del contenido esencial del derecho de libertad religiosa y en todas las materias que afectando al hecho religioso tienen una dimensión jurídica con relevancia pública ${ }^{3}$.

Piense el lector que el derecho eclesiástico como disciplina no agota su contenido en el derecho de libertad religiosa o de conciencia, así historia, la política legislativa, la sociología, y el derecho comparado entre otras, se presentan como disciplinas de necesario manejo para el operador jurídico cuando analiza temas de derecho eclesiástico.

De modo que por razón de método el derecho eclesiástico se presenta como una materia "interdisciplinaria”, y por razón de fuentes como un derecho con un sistema de fuentes "transversal". Circunstancias que han dificultado su estudio y aplicación práctica, como se observa en la jurisprudencia poco uniforme del Tribunal Constitucional peruano.

Para paliar esos problemas se necesita no solo una ley de libertad religiosa, sino también una coherente aplicación de los principios esenciales que vertebran esta disciplina, y sobre todo, aclarar su radical diferenciación con respecto a cualquier otro derecho confesional. Es esa una labor de gran escala que ahora planteamos para seguir ahondando en ella en futuras investigaciones.

\section{LA IMPORTANCIA DE LA LEY 29.635 DE LIBERTAD RELIGIOSA}

El proceso histórico que lleva a la incorporación de una tabla de derechos de la persona en los textos constitucionales se inició ya en el S. XIX pero no será hasta entrado el s. XX que ese proceso culmine y podamos de ese modo afirmar que un modelo protector de los derechos fundamentales de la persona está extendido por todo el mundo civilizado. La misma Iglesia católica revisó su posición doctrinal inicialmente crítica y en el contexto del Concilio Vaticano II impulsó la aprobación de un documento tan esencial como es la Declaración Dignitatis Humanae que declara el derecho de libertad religiosa de toda persona humana ${ }^{4}$. La regulación interna se completa con una importante red de normas internacionales que dotan de contenido y protección a los derechos de la persona.

El Perú siguió ese proceso constitucional en 1979, reconociendo el derecho de libertad de conciencia y religión, aunque pospuso el desarrollo legislativo de ese derecho hasta diciembre de 2010. En el caso peruano la incorporación constitucional del derecho de libertad religiosa significó también un cambio de un modelo confesional católico a un modelo de colaboración, de ahí la importancia que hubiese tenido disponer en su debido momento de una ley de desarrollo que orientase el trabajo a los operadores jurídicos 5 .

\footnotetext{
3 Resultado de esta actividad docente en la Universidad de Piura son las publicaciones relacionadas con el derecho eclesiástico. CARPIO, MosquERA. Estos trabajos generales se completan con artículos y colaboraciones obra de profesores peruanos dedicados también al estudio de temas de derecho eclesiástico entre los que debemos señalar a Carlos Valderrama, Gonzalo Flores, José Antonio Calvi del Risco, Juan José Ruda Santolaria entre otros.

4 Su aprobación provocó cambios legislativos importantes en aquellos territorios confesionalmente católicos que incorporaron entonces leyes de libertad religiosa para los ciudadanos no católicos).

5 Para mayor detalle sobre el particular véase, MosQuera (2011).
} 
La importancia de la Ley 29.635 es mucha pero no menor es la de su Reglamento de desarrollo puesto que es en él donde encontramos la formulación práctica del nuevo modelo. Los convenios de colaboración con las entidades que alcancen notorio arraigo en la sociedad peruana son el eje de ese desarrollo legislativo al que le avizoramos una larga y dinámica vida.

\section{DERECHO ECLESIÁSTICO COMO RAMA JURÍDICA SINGULAR}

Para entender la posición que esos acuerdos ocuparán dentro del sistema jurídico peruano resulta indispensable conocer y comprender alguna de las singularidades jurídicas que tiene el sistema de fuentes del derecho eclesiástico que no se reduce a la ley de libertad religiosa ${ }^{6}$. El derecho eclesiástico es una rama jurídica relativamente joven, sobre todo en aquellos países conun pasado marcado por la confesionalidad religiosa como es el caso latinoamericano ${ }^{7}$.

El derecho eclesiástico toma como fuente principal al texto constitucional, cuya ayu$\mathrm{da}$ es fundamental en los momentos en que la ley de desarrollo se demoraba y el operador jurídico tiene que extraer del texto constitucional el contenido esencial del derecho. Por fortuna, el intérprete constitucional cuenta con el apoyo de los tratados internacionales. Junto a ellos encontraremos los acuerdos que el estado firme con las entidades religiosas.

En un tercer nivel normativo encontramos a las fuentes de origen unilateral, que provienen de la capacidad de creación normativa que tiene el legislativo o el ejecutivo y que por razón material regulan algún aspecto de interés del fenómeno religioso en el orden público. Transversalidad e interdisciplinariedad, dos singulares características del derecho eclesiástico como disciplina jurídica. Lo que en la práctica significa que la solución de esas controversias que derivan del impacto social que tiene el hecho religioso en una sociedad plural, tendrán que ser analizadas aplicando normas y principios que tienen su origen en ramas dispersas del ordenamiento jurídico, pero que resultan estar unidas porque en ellas encuentra su protección el derecho de libertad religiosa.

\section{TÉCNICAS DE RELACIÓN ENTRE ORDENAMIENTOS}

Llegados a este punto puede resultar relevante incorporar la teoría del ordenamiento jurídico que ROMANO ${ }^{8}$ construye sobre el concepto de institución jurídica con capacidad normativa. Las instituciones con esa capacidad serán creadoras de derecho primario, siendo la relación entre esos ordenamientos primarios el eje central de su teoría.

Esta técnica tiene una gran utilidad jurídica cuando están a punto de tomar carta de naturaleza los convenios de colaboración con las entidades religiosas distintas a la católica. Habrá que esperar a que dichos convenios vean la luz, pero desde este momento podemos intuir la importancia que tendrá el adecuado funcionamiento de las técnicas de recepción entre ordenamientos, civil y religioso, y con ello facilitar la convivencia social.

\footnotetext{
6 Patiño (2011).

7 Navarro (2002).

8 Romano (1963).
} 


\section{CONCLUSIONES}

El pluralismo social y las circunstancias que visualizan un modelo en proceso de cambio dan a entender que las situaciones de tensión en el ejercicio del derecho de libertad religiosa seguirán siendo numerosas, como lo demuestran el aumento de casos con temática religiosa que ha llegado hasta el Tribunal Constitucional en los últimos años.

De ahí que podamos afirmar que el campo de trabajo para el estudioso del derecho eclesiástico tiene en Perú un interesante terreno de investigación, puesto que la normativa reciente tiene por delante una etapa de aplicación que nos presenta un amplio abanico de posibilidades ricas para la doctrina y la jurisprudencia. Estamos en un momento de cambio y el derecho debe estar listo para dar las adecuadas respuestas que la sociedad espera.

Esa respuesta debe sostenerse sobre la base de una adecuada definición y correcta aplicación de los principios que vertebran el derecho eclesiástico del estado.

Nada más y nada menos para una joven disciplina que tiene mucho que decir en temas de relevancia para la solución de conflictos y tensiones ideológicas dentro de las sociedades plurales actuales.

\section{BIBLIOGRAFÍA CITADA}

Carpio Sardón, L. Andrés. (1999) La libertad religiosa en el Perú. (Lima. Colección jurídica. Universidad de Piura).

González del Valle, José .María. (1997) Derecho eclesiástico español. (Oviedo. Universidad de Oviedo).

Mosquera Monelos, Susana. (2005) El derecho de libertad de conciencia y de religión en el ordenamiento jurídico peruano. ( Lima. Palestra).

Mosquera Monelos, Susana. (2011) "La cuestión religiosa en el Perú a propósito de la Ley No 29635 de libertad religiosa”, (pp. 291-203) en Gaceta Constitucional. N³8. Febrero.

Navarro Floria, J. G. (2002) "La libertad religiosa y el Derecho eclesiástico en América del Sur", (pp. 28-53) en Conciencia y libertad. $\mathrm{N}^{\circ} 14$.

Pacheco Gómez, M. (2004) La separación de la Iglesia y el Estado en Chile y la diplomacia vaticana. Con la colaboración de Muñoz Sandobal, J. y García-Huidobro BeCerRA, C. (Santiago. Ed. Andrés Bello).

PATIÑo ReYes, A. (2011) Libertad religiosa y principio de cooperación en Hispanoamérica. (México. UNAM).

Romano, S. (1963) El ordenamiento jurídico. (Madrid. Instituto de Estudios Jurídicos).

Salinas Araneda, C. (2004) Lecciones de Derecho Eclesiástico del Estado de Chile. (Valparaiso. Ediciones Universitarias de Valparaiso).

\section{NORMAS CITADAS}

LEY $\mathrm{N}^{\circ}$ 29.635, Ley de libertad religiosa de 10 de diciembre de 2010.

Decreto Supremo No 010-2011-JUS, Reglamento de la Ley N²9.635, Ley de libertad religiosa. 